\title{
The 7-Circle Model: A Practical and Coherent KM Model for Managing Organizational Knowledge
}

\author{
Andrew C. Ologbo \\ Universiti Teknologi Malaysia (UTM), Faculty of Management, 81310 Skudai, Johor \\ andrewologbo@yahoo.com \\ Khalil Md Nor \\ Universiti Teknologi Malaysia (UTM), Faculty of Management, 81310 Skudai, Johor \\ kmdnor@management.utm.my, m-khali@utm.my
}

\section{Doi:10.5901/mjss.2015.v6n4s1p120}

\section{Abstract}

\begin{abstract}
The purpose of this paper is to propose a practical model, named 7-circle model that attempts to provide a simple practical framework for managing organizational knowledge. A review of KM models and theories was carried out. The shortcoming of an existing holistic KM model in linking theory to practice had sparked the initiative of this model. This paper concludes by presenting a simple and coherent model for KM practical application at organizational unit level. The model identifies seven interdependent and mutually reinforcing components in which things must consistently go right in any organization that seeks to manage its knowledge for organizational success and competitive advantage. The 7-circle model provides a coherent guide for harmonizing KM mechanisms and technologies as well as coordinating the interaction between people and technology in knowledge management. Much KM literature promotes a universal view suggesting a one-size fits all approach to managing organizational knowledge but this model suggests a contingency view of knowledge management, arguing that each organization is unique with its unique knowledge resources therefore should manage its knowledge in its unique simple way.
\end{abstract}

Keywords: Knowledge management, Knowledge management initiative, Organizational knowledge, KM people, 7-circle model.

\section{Introduction}

As societies are gradually transforming into "knowledge societies", knowledge and knowledge management (also referred to as KM) are increasingly attracting the interest of both governments and private organizations. Many practitioners and academic researchers had noted that knowledge is a crucial asset that has to be utilized and managed efficiently and effectively for organizations' success and competitive advantage (Lin, 2011; Becerra-Fernandez and Sabherwal, 2001; Darroch, 2005; Du Plessis, 2007; Donnelly, 2008). Davenport et al. (1998) defined knowledge as "a form of high value information (either explicit or tacit) combined with experience, context, interpretation and reflection that are ready to be applied to decisions and actions". Knowledge had being defined and viewed in diverse perspective.

A major discussion issue in $\mathrm{KM}$ domain is on determining whether knowledge is a process or an asset. However, it is pertinent to clear such issues by noting that knowledge can be viewed as a state of mind, a thing or an object, a process, a capability and as a condition of having or having access to information. As a state of mind, knowledge can be viewed as enhancing individuals' personal knowledge so that they can apply it effectively to their organization. As an object or a thing, knowledge can be stored, retrieved and manipulated (Wasko and Faraj, 2000; Haslinda and Sarinah, 2009). As a process, knowledge can be viewed as the application of expertise, thus knowledge is dependent to human action. As a capability, knowledge is viewed to have a potential to produce future action; as noted by Alavi and Leidner (2001), knowledge has the capability to build intangible assets and intellectual capital. Lastly, as a condition, knowledge can be viewed as having access to information thus it is closely linked to the object view.

Although there are different views in terms of definition, however these diverse views posit that knowledge in any organizations should be structured in a way that makes it easily accessible and retrieved. This is the role of knowledge management. Hence, knowledge management according to Tiwana (2000) is the management of organizational knowledge for creating business value and generating competitive advantage. Knowledge management enables the creation, communication, and application of knowledge of all kinds to achieve business goals. Knowledge management has no universal definition. However, it is worth noting that knowledge management encompasses theories, models, 
initiatives, processes, mechanisms and technologies that support the creation, development, protection, sharing and application of knowledge resources. Despite the great role of knowledge management practices, organizational knowledge still seems very difficult to manage. For example, Blacker (1995) noted that knowledge is disorganized and difficult to manage, multifaceted and complex, being situated and abstract, implicit and explicit, distributed and individual, physical and mental, developing and static, verbal and encoded. Many organizations have a well-known pool of knowledge resource distributed through out their organization while others have knowledge in the wild or unaware of the existence of their knowledge resources. Therefore, for firms to effectively manage their knowledge, they need a simple but coherent and practical model to help them engage in the activities that is channeled to build, organize, sustain, and leverage these intellectual and knowledge resources.

Based on this need, this paper formulates some research questions. The first research question ponders why there is no existing simple and practical KM model to guide organizations in KM implementation? The second queries that given top management support for KM initiative (and other relevant factors), how would a firm manage its knowledge resources? The third asks, is technological factor more important than social factors when implementing knowledge management? Finally, despite some existing KM model, why is there still a low rate of KM adoption in many parts of the world? To proffer answers for these research questions, the objective of this paper is to develop a model that shows how the seven key aspects of KM are mutually reinforcing; coherent and consistent in managing knowledge in organizations in order to help practitioners and researchers link theory to practice. This paper has contribution to knowledge and practice as it presents a simple model which serves as a blueprint to champion KM implementation in firm regardless of their size or type. The next section would briefly highlight some previous knowledge management theories and models before presenting the 7-circle model.

\section{Previous Theories and Models of Knowledge Management}

Nonaka is one of the pioneers in the field of knowledge management. Nonaka's KM model is centered on the concepts of $\mathrm{SECl}$ and $\mathrm{Ba}$. The SECl (socialization, Externalization, Combination, and Internalization) model surfaced in 1991 and was used to describe ways knowledge (tacit and explicit) is created, transferred and re-created in firms (Nonaka, 1994). The Ba concept which in similar to the concept of place in English, was introduced by Nonaka and Konno (1998). According to them, a Ba in knowledge management is a space for dynamic knowledge conversion. Thus, the organization environment is crucial for knowledge creation and management (Nonaka and Takeuchi 1995).

Kogut and Zander's (1992), knowledge management theory was among the foundation builders of the knowledgebased theory of a firm which established that knowledge plays a strategic importance as a source of competitive advantage. They suggested that knowledge (information and know-how) is not only embedded in individuals but also in mechanisms by which individuals cooperate in a social community. Wiig (1997), another pioneer in the field of KM through his three pillars of knowledge management model, proposed that the foundation of KM encompasses of the way knowledge is created, applied in problem solving and decision-making which is seen in the culture, technology and procedures of an organization. In his work, the three pillars were recognized as knowledge exploration, knowledge value assessment and its active management. Hedlund and Nonaka (1993) elaborated on Nonaka's model, suggesting that knowledge transfer could be very complex and complicated. Their model developed the four levels of carriers of knowledge in organizations, which was classified into the individual, the group, the organization and the inter-organization sphere of influence. They contributed remarkably by suggesting that the core of organization competitiveness, success or failure can depend on how the organizations create, transfer, share and exploit their knowledge assets.

A Swedish firm known as Skandia, posited Skandia intellectual capital model of knowledge management as an approach for assessing intellectual capital. The model focuses on the importance of human, equity, customer and innovation in managing the flow of knowledge within and outside the firm. According to Lank (1997), Skandia's KM model is a scientific approach, which ignores social and political facets of knowledge management. McAdam and McCreedy (1999) reviewed Demerest's knowledge management model, noting that the model accentuate on the construction of knowledge within the firm in a bid to address the limitation of Skandia model. The model presupposes that constructed knowledge is personified within the organization not only through explicit programs but also through a process of social interchange. This construction did not limit its view to scientific paradigms but included social paradigms of knowledge construction (McAdam and McCreedy, 1999).

Stankoshy and Baldanza (2001) knowledge management model accentuated that enabling factors such as organization structure, organization culture, leadership, technology and learning are very crucial for knowledge management. The model also recognizes that knowledge management is a product of many other disciplines such as cognitive science, psychology, communication, finance economics, human resource, management, strategic planning, 
system thinking, computer technologies, software and library science, system engineering and so on. Frid's (2003) knowledge management model provided a framework known as the KM maturity assessment levels and the five levels of KM implementation. This five maturity levels are knowledge chaotic, knowledge aware, knowledge focused, knowledge managed and knowledge centric. This model emphasized on the unique and diverse activities that organizations should focus on are institutionalizing successful initiatives and assessing intellectual assets.

No doubt, all these models discussed above had contributed significantly to the field of KM yet there is still poor adoption rate of KM. Many firms do not know how to adopt KM because theory covers a broad spectrum of concepts and numerous frameworks (Levett and Guenov, 2000). Lavett and Guenov (2000) noted that there is no detailed model for developing a particular KM strategy probably because KM is a recent management philosophy and it is diverse within organizational working environments and unique KM requirements. However, there are existing useful KM models that elucidated approaches to predict KM success and to design effective KM. A remarkable example of such models is Jennex and Olfman (2006)'s KM success model. The authors proposed the KM Success Model as an explication of the widely accepted DeLone and McLean $(1992,2003)$ IS Success Model. Jennex and Olfman (2006)'s KM success model is derived from a longitudinal study of knowledge management in an engineering firm and the existing evidence of KM success factors in the literature.

Jennex and Olfman (2006)'s KM success model made a significant contribution to knowledge in the field of KM by harmonising the role of system quality, knowledge quality and service quality in impelling the user's intention to use KM, the satisfaction they derive using KM and their net benefits in terms of individual performance at the workplace. System quality is the technological resources which is made up of KM level and KM form, knowledge quality is the KM strategy/process (in terms of its richness and linkages) while service quality, is the management support (IS KM Service Quality and User KM Service Quality). This model emphasised the operative ways to generate the right knowledge and the effective ways to use organizational knowledge. Interestingly, widely-adopted taxonomy of KM recognizes three schools of thought namely: behavioral, economic and technocratic (Handzic, 2011). In a bid to provide a simple and more applicable model for practitioners necessitated the introduction of the 7-circle model. This proposed model brings together different views of previous KM theories and models and provides a nexus among behavioral, economic and technocratic KM schools of thought.

The 7 circle becomes necessary in a bid to help link theory to practice because despite the emphasized importance of KM in the literature, there is still a poor rate of KM adoption in many parts of the world. Scholars like Lavett and Guenov (2000) noted that there is no detailed model for developing a particular KM strategy probably because KM is a recent management philosophy and it is diverse within organizational working environments and unique KM requirements. Raub and Von Wittich, (2004) expressed that although knowledge management is applauded as an approach that will foster organizational performance and economic growth, yet the concept is surrounded by misunderstanding and misconception of its use. This has limited the extent to which the larger business community has embraced and employed knowledge management practices deliberately. Part of the reasons for low rate KM adoption in many parts of the world could probably be attributed to its multiplicity. Knowledge management is highly multidisciplinary and as an emerging science, knowledge management has drawn from a wide range of established disciplines such as organizational learning initiated (by Senge, 1994), networking (by Powell, 1990), intellectual capital (by Brooking, 1996) social construction (by Innes, 1992), communities of practice (by Lesser et al., 2000), and social interaction (by Nonaka and Takeuchi, 1995) thus making it difficult or rather complicated for practitioners to apply these complexity into practice.

It is relatively apparent that organizations that can efficiently capture the knowledge embedded in their organizations and deploy it into their operations, productions and services would have an edge over their rivals. Thus, the 7 circle becomes necessary as it emphasizes practical ways which would help organizations leverage and utilized their knowledge resources. Recent research indicates that knowledge management approaches are predominantly focused on information technology framework. According to researchers (such as Beesley, 2004; Call, 2005; Cooper, 2006), knowledge management failures could be attributed to an over-emphasis on technologies and insufficient acknowledgement of the "humanness" of knowledge. The 7 circle is useful and necessary because it harmonizes the interaction between human aspect and technological aspect of knowledge management.

Despite the importance of $\mathrm{KM}$ to organizations, one could ponder why there is no existing simple and practical KM model to universally guide organizations in KM implementation. In other words, one could wonder that despite some existing KM models, why is there still no single universally accepted KM adoption model? To provide some answers to the questions, the 7 circle model posits 7-keys ways in which things must go right to manage organizational knowledge resources. The circles of the model, address issues relating to strategic focus of $\mathrm{KM}$, the cultural aspects, the importance of people dimension and human aspects, social interaction of mechanisms, technological aspect, technology-people interactions, and the need for KM motivation and reward system. 


\section{The Components 7-Circle Model}

The 7-circle model is made up of seven components namely: KM initiative, KM culture, KM people, KM mechanisms, KM technology, KM interaction and KM motivation. The seven components are used to explain the key ways in which things must go right in managing organizational knowledge. These seven components are presented in circles and explained as follows:

\subsection{Circle 1: Develop KM initiative/strategy}

The development of KM initiative or KM strategy could be seen a strategic focus of the knowledge management process. There is need for any firm that wants to manage its knowledge to first recognize the need for knowledge, the uniqueness of its organizational knowledge and the ways to promulgate it. KM initiative could be top-down or bottom-up approach, middle-up or middle-down approach. This implies that KM initiative is dynamic and could germinate from any level of the organization. However or whatever way the KM is initiated either by top management, line managers or employees at the operational level; it is important for the top management to provide investment in cash, strategy, flexible policy and through commitment to monitor the process while it is the responsibilities of employees at all level to contribute their time, participation and support to the process. A bid to provide guidelines for k-strategy, April (2002) expressed the need for organizations to provide the inter-linkage between strategic architecture, set of complementary resource combinations and pool of assets/resources in order to sustain their advantage.

In KM literature, three different meanings are associated with the term KM strategy. The most common of them interprets it as an approach to KM, the second meaning relates KM to strategic management, and defines KM strategy as knowledge strategy, critical element of knowledge-based competitive strategy while third meaning, usually employed in practical contexts, conveys a KM implementation strategy. All three meanings vividly clarify on the relation between technology, KM and strategy (Saito et al. 2007). Greiner et al. (2007) express a strong need for the alignment of KM strategy in accordance to the organizational business strategy. The explained KM strategy as codification and personalization while business strategy as innovation and efficiency and concluded the most successful knowledge management projects were those that the knowledge management objectives and strategy goals concurred with the firm's business objectives and strategy goals.

\subsection{Circle 2: Create and recognize KM culture}

Once the KM initiative is developed, it is important for the organization to create KM culture. This means a culture that recognizes that knowledge resides in its people and that the greatest asset of the organization is its people. The culture of an organization is a set of assumptions, core values held by its people that govern their behavior, communication and reaction to its environment (Schein, 1985; Ott, 1989) and about what the organization strive to attain as well as how it would achieve it. Ergo, treating people as a key resource and building a viable organizational environment conducive for knowledge management is essential.

Organizational culture has been identified as a major factor that can foster or inhibit knowledge management and it is now conventional wisdom that culture influences on a wide variety of individual, group and organizational KM choices and outcomes (Al-Alawi, 2007; Lopez, 2004; King, 2008). Organizational culture can substitute formal control mechanisms (procedures and policies) giving way to a social setting where values are implanted in members' belief and behavior (Khalil, 2006). Furthermore, organizational culture should be lean and encouraging for KM by eliminating fear, criticism and punishment. Organization culture should not be too autocratic or bureaucratic but should embrace innovative or democratic culture as an integral part of its component. King (2008) posited that the relationships between $\mathrm{KM}$ and culture are an important part of the conventional wisdom of KM. However, culture-KM relationship may not be as simple and straightforward as many people believe it to be. The author addressed culture at five levels that are relevant to KM practice and success: National culture, Organizational culture, Organizational climate, Sub-unit culture and organizational subcultures, Team climate. In sum, the success or failure of KM in organizations is dependent on its culture which influences the behaviours and attitudes of the employees.

\subsection{Circle 3: Choose the right KM people}

Knowledge is embedded in people. People are the original holders of knowledge and without their willingness and cooperation to share it, all efforts channeled to manage knowledge resources may probably be lavished. Managing 
people is managing knowledge and managing knowledge is managing people (Davenport and Volpel (2001). Knowledge is created and applied in the minds of people and in future organizations will realize that the knowledge it possess is the most valuable aspect of their organization (Davenport and Volpel 2001). Choosing the right people or employees to champion the KM process is very essential. This means identifying the employees that have the flair and charisma to promote the KM process. Weeks (2004) described KM people as enablers and catalysts for creating and managing organizational knowledge. They may be also referred to as knowledge brokers and should appear in every department, unit and in teams at the organizational level. Corporate KM staff, the departmental knowledge brokers and the KM council of experts should be knowledgeable and devoted irrespective of their gender. They should work in teams and should form communities that may be referred to as fields experts, council of experts, health check teams, knowledge champions or whatever names the organization feel to address them. These KM people or experts lead by action. They are responsible for convincing all employees to create, share and apply knowledge. They help to prevent re-inventing the wheel and to retain or store reusable knowledge in the organization. The treating people as assets are essential to encourage employee retention and to retain knowledge from being lost.

\subsection{Circle 4: Choose the right KM mechanisms}

KM mechanisms are complex and it is not a one size fits all. Therefore, each organization should identify and choose the right mechanism to support its people and technologies. In literature many successful organizations like Mckinsey, Siemens, Danone, Kraft Food and so on, had adopted mechanisms such as communities of practice (CoP), central business unit (CBU), practice Olympic, focus groups, marketplace and best practices (Bartlett, 1996; weeks 2004 and Leidner et al., 2006). These communities of expert help to disseminate organization knowledge across their branches, regional offices and global headquarters. The right mechanism is the one that integrate formal and informal approach. An example of an informal approach may be groups or teams of employees who may not be officially recognized by the management. An example is "Kraken" as described by Weeks (2004), as an underground group that probably provides more useful exchange of information than a company-certified group could. The right mechanism integrates process and practice approach. The process approach formalizes controlled and codification of organizational knowledge through processes and technologies (Hansen et al., 1999) while practice approach is social and uncontrolled environments that facilitate the sharing of tacit knowledge through people (Leidner et al., 2006). The integration of both approaches will enable the organization to position itself for competitive advantage.

\subsection{Circle 5: Choose the right KM technology}

The role of technology in KM is inevitable. Information technology has been suggested as an important factor in knowledge repositories, data mining, decision support systems, storage and easily retrieval of knowledge resources (Handzic, 2011). I.T has been useful in connecting people to information and has enhanced communication flow among employees of organizations. The importance of technology in KM cannot be overemphasized. In this complex technology epoch, choosing the right technology is an added advantage for KM success. The right technology is the effective, accessible, cost-effective technology that is easy for employees to use to enhance the KM processes and performance. The technology a firm should choose must be in consonant with the ability of employees the purpose of KM and the culture of the organization. Park et al (2004) expressed that culture has critical attributes that promotes knowledge management technology implementation success. Organizations can choose from identified technologies in literature such as the lotus note, web portal, intranet, live-link, PDnet, blogs, Internet forum, SAP (business software) system, group email, databases, data mining, best practices and lesson learned databases, video conferencing, electronic discussion groups, computer-based simulations, expert systems, management information systems, troubleshooting systems, case-based reasoning systems and lots more (Becerra- Fernandez et al., 2004). KM technologies and KM mechanisms, supports knowledge sharing as well as application systems by facilitating the quick and easy flow of information and knowledge within and outside the organization.

\subsection{Circle 6: Co-ordinate KM interaction}

The conflict between people and technology is a major challenge to KM process. Therefore for a successful implementation of $\mathrm{KM}$, it is crucial to co-ordinate the interaction and conflict between people and technology. Coordinating the KM interaction enables firms to maintain equilibrium of human-centered approach and technologycentered approach. The KM people have a role to play here. They have to ensure that the usage is structured and formal 
because some employees may feel reluctant to use technologies. This may be evident in their inability to post or share knowledge using the Internet or database. Some employees may even feel reluctant to access knowledge that is already posted by other employees. This could be resolved through training and development program, on-the-job training or hands-on training program, knowledge skills acquisition program, and networking attitude program. An integrated team of human resource department and the IT department should provide these training. Bhatt (2001), Handzic (2011) and Rhodes (2008) emphasized the importance of harmonizing both social and technical enablers of knowledge management. According to the authors, organizational people, organizational culture, structures, work processes, and technologies are tightly interconnected and interact closely to be of value to organizational performance. KM interaction would help maintain the balance between Personification approach (human-centered approach for sharing tacit knowledge) and codification approach (technology-centered approach for sharing explicit knowledge) to mitigate KM failure (Handzic, 2011). It is now made obvious in KM literature that KM is $80 \%$ organizational culture and human factor and 20\% technological factor (Becarra-Fernadez et al (2004); therefore for a successful KM implementation, it is crucial to properly co-ordinate the interaction and conflict between people and technology. KM methodologies and technologies must enable effective ways to elicit, represent, organize, re-use, and renew this knowledge.

\subsection{Circle 7: Implement KM motivation system}

Motivation is very important. As explained by the Social exchange theory (SET) by Homans, (1958) and Blau (1964), people make social decisions based on perceived costs and benefits. This implies that employees with regards the central tenet of the social exchange theory, may be willing or unwilling to share their knowledge or participate in KM process based on the perceived benefits they could gain from such a relationship. Rewards and incentives create an organizational climate of co-operation, innovation and learning. Thus, reward is a very good form of KM motivation. Wong (2005) noted that unless employees are motivated, no amount of infrastructure, technological intervention, and investment can make KM practice to be effective. A good motivation system encompasses management support, recognition, respect and reward (both tangible and intangible). Employees official workload may hinder them from participating in knowledge sharing and networking attitude but through proper reward, such employees may be motivated to participate. A good KM evaluation structure should be put in place to recognize and reward individuals or teams that contribute significantly to the KM process.

\section{The 7-circle model}

As the planets revolve around the sun, so does the notion of the 7-circle model revolve around KM in organizations that have the enthusiasm to manage its knowledge to improve their processes, products, productivity, performance and overall business success.

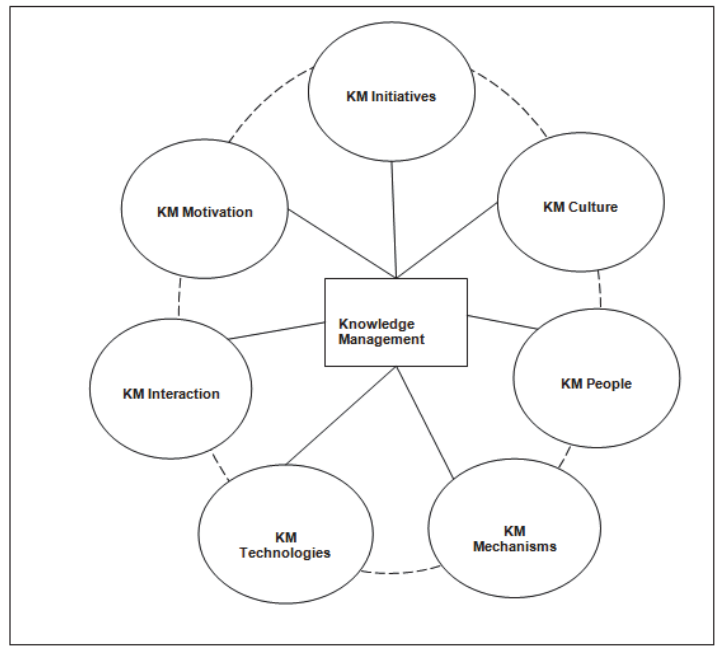

Figure 1: The framework of the 7-circle model 
The 7-circle model can be described as the seven key aspects of KM that must be mutually reinforcing, coherent and consistent in managing knowledge in organizations. The model emphases the seven interdependent ways in which things must consistently go right in any organization that seeks to manage its knowledge for organizational success and competitive advantage. This model is simple, coherent and applicable to both small and larger firms and it provides a substantial explanation in a concise manner to guide practitioners adopt it into practice.

Like the circle, the 7-circle model explains that managing knowledge in organizations has no definite end, which means that managing knowledge and learning must be a continual process, institutionalized and imbibed into the organization culture for the sustainability of competitive advantage. The model would be utilized by organizations in consonant with the components of the circles. The circles address the importance for the organization to have strategic focus of KM, then recognize and put into play the cultural aspects, the importance of people dimension and human aspects, social interaction mechanisms, technological aspect, technology-people interactions, and KM motivation and reward system. KM practitioners could use this model to drive and implement KM strategies in their firms. This model would provide a direction for future academic scholars and could also help them to build on this model in order to push the boundaries of knowledge forward.

\section{The Rationale Behind the 7-Circle Model}

The rationale behind the 7-circle model is the notion of a puzzle which depicts seven key aspects which must work in consonant for effective knowledge management. The notion of the puzzle highlights strong emphasis that an exclusion of one puzzle means an incomplete knowledge management process. The 7-circle argues that each organization is unique with its unique knowledge resources therefore should manage its knowledge in its unique simple way by starting the implementation its KM practice from any of the components. The 7-circle model is generated from previous KM models. The methodology employed is the review of existing KM theories and models. The prior KM models where grouped into themes (technology, people, and strategy) in accordance to their area of emphasis. Based on these themes, the researchers were able to identify and group these themes to form the circles of the model. Each circle is used to emphasis themes that organizations and practitioners must consider while implementing KM.

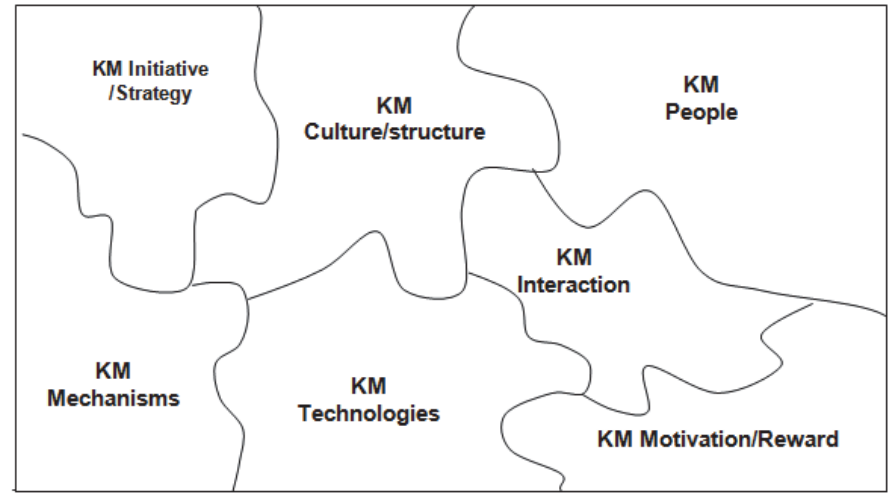

Figure 2: The Rationale for 7-Circle Model

\section{Conclusion}

Managing organizational knowledge and learning has been a challenging venture for organizations, institutions and societies. The challenges are accentuated when there is no clear holistic practical model, or framework for managing organizational knowledge. Hence, the 7-circle model had been present in a simple and clear manner. Thus, practitioners and researchers should adopt this proposed research model as a blueprint or framework to champion their KM implementation. It will help them to stop relying entirely on knowledge consulting firms before taking bold steps in championing their KM. Every organization has its unique organizational knowledge; hence to effectively manage it lies in the hands of its people. It is important for top management and managers to note that employees cannot be forced to create or share knowledge. They do it naturally or persuaded to, when there is much conducive organizational 
environment, existing KM culture, clear KM strategy, infrastructure, mechanism, technologies and motivation system in place.

Managers should use this model to identify what resources and benefits that are most desired by its people to trigger their sense of obligation to create, share, and apply knowledge. This model makes it clear that top management should understand that KM process is a long-term and continual process that requires consistent interaction of people, mechanisms and technologies in an enabling environment and organizational culture. In sum, it is pertinent to state that the 7-circle model differs from other KM theories because it brings together diverse views and propositions of existing KM theories and models to a posit a simple framework which coherently show strategies on how organizational knowledge should be managed. The 7 circle model harmonizes the nexus among behavioral, economic and technocratic KM schools of thought and unlike Skandia's KM model which is merely based on scientific approach, 7-circle model considers social and political facets of knowledge management.

\section{References}

Al-Alawi A.I., Al-Marzoogi, N.Y and Mohammed, Y.F (2007), "Organizational culture and knowledge sharing: critical success factors", Journal of Knowledge Management, Vol. 11 No. 2, pp. 22-42.

Alavi, M. and Leidner, D., (2001), Knowledge Management and Knowledge Management Systems: Conceptual Foundations and Research Issues. MIS Quarterly, Vol. 25 No. 6, pp. 95-116.

April, K.A. (2002), "Guidelines for developing a k-strategy", Journal of Knowledge Management, Vol. 6 No. 5, pp. 445-56.

Bartlett, C. (1996). Mckinsey and Company: Managing knowledge and Learning, Case 9-396-357, Boston, MA: Harvard Business School.

Becerra-Fernandez, I. and Sabherwal, R. (2001), Organizational knowledge management: a contingency perspective. Journal of Management Information Systems, Vol. 18 No.1, pp. 23-55.

Becerra-Fernandez, I., Gonzalez, A., and Sabherwal R. (2004), Knowledge Management: challenges, solutions and technologies. Prentice Hall, Upper Saddle River.

Beesley, L.G (2004), "Multi-level complexity in the management of knowledge networks", Journal of Knowledge Management, 8 (3), 71 100.

Bhatt, G.D (2001), Knowledge management in organizations: examining the interaction between technologies, techniques and people. Journal of Knowledge Management Vol. 5 No. 1, pp. 68-75.

Blackler, F. (1995) Knowledge, Knowledge Work and Organizations, Organization Studies, Vol. 16 No. 6, pp. 1021-1046.

Blau, P. (1964). Exchange And Power In Social Life. New York: John Wiley \& Sons.

Call, D. (2005), "Knowledge management - not rocket science", Journal of Knowledge Management, 9 (2), 19-30.

Cooper, C. (2006), "Knowledge management and tourism", Annals of Tourism Research, 33 (1), 47-64.

Donnelly, R. (2008), "The management of consultancy knowledge: an internationally comparative analysis", Journal of Knowledge Management, Vol. 12 No. 3, pp. 71-83.

Darroch, J. (2005), Knowledge management, innovation and firm performance, Journal of Knowledge Management, Vol. 9 No. 3, pp. 101-115.

Davenport, T.H., De Long, D.W and Beers, M.C. (1998). Successful knowledge management. Sloan Management Review, Vol. 39 No. 2, pp. 43-57.

Davenport, T.H and Volpel, S.C (2001), The rise of knowledge towards attention management, Journal of Knowledge management, Vol. 5 No. 3, pp. 212-222.

Du Plessis, M. (2007), The role of knowledge management in innovation. Journal of Knowledge Management, Vol. 11 No. 4, pp. $20-29$.

Frid, R (2003). A Common KM Framework For The Government Of Canada: Frid Framework For Enterprise Knowledge Management, Canadian Institute of Knowledge Management, Ontario.

Handzic, M. (2011), Integrated socio-technical knowledge management model: an empirical evaluation, Journal of Knowledge Management, Vol. 15 No. 2, pp. 198-211.

Hansen, M.T., Nohria, N., and Tierney, T. (1999). What's your strategy for managing knowledge? Harvard Business Review, Vol. 77 No. 2, pp. 106-115.

Haslinda, A. and Sarinah, A. (2009). A review of knowledge management models. Journal of international social research, Vol. 2 No. 9 , pp. 187-198.

Hedlund, G. and Nonaka, I. (1993). Models of Knowledge Management in the West and Japan. In Lorange, B.,Chakravarthy, B., Roos, J. and Van de Ven, H. (Eds) Implementing Strategic Process, Change, Learning and Cooperation, Macmillan, London, pp. 11744.

Homans, G. C. (1958). Social Bahavior as Exchange: American Journal of Sociology, Vol. 63 No. 6, pp. 597-606.

Jennex, M.E and Olfman, L (2006), A Model of Knowledge Management Success, International Journal of Knowledge Management, 2(3), 51-68.

King, W.R (2008),"Questioning the conventional wisdom: culture-knowledge management relationships", Journal of Knowledge Management, Vol. 12 No. 3 pp. $35-47$.

Kogut, B. and Zander, U. (1992) Knowledge of the Firm, Combinative Capabilities, and the Replication of Technology, Organization 
Science, Vol. 3 No.3, pp. $383-97$.

Lank, E. (1997). Leveraging Invisible Assets: The Human Factor, Journal of Long Range Planning, Vol. 30 No. 3, pp. 406-12.

Leidner, D., Alavi, M. and Kayworth, T. (2006). The role of culture in knowledge management: A case of two global firms. International journal of e-collaboration, Vol. 2 No.1, pp. 17-40.

Levett, G.P and Guenov, M.D (2000), A methodology for knowledge management implementation, Journal of Knowledge Management, $4(3), 258-269$.

Lin, H.F (2011), Antecedents of the stage-based knowledge management evolution, Journal of Knowledge Management, Vol. 15 No. 1 , pp. 136-155.

Lopez, S.P., Montes Peon, J.M. and Vazquez Ordas, C.J. (2004), "Managing knowledge: the link between culture and organisational learning", Journal of Knowledge Management, Vol. 8 No. 6, pp. 93-104.

Greiner, M.E, Bo"hmann, T. and Krcmar, H. (2007), A strategy for knowledge management, Journal of Knowledge Management, Vol 11 No.6, pp. 3-15.

Nonaka, I. (1994). A Dynamic Theory of Organizational Knowledge Creation. Organization Science, Vol. 5, pp. 14-37.

Khalil, M.N (2006), Knowledge management: Does the organizational culture matter? Journal Technology, Vol. 8, pp. 1-12.

Nonaka, I. and Konno, N. (1998), The concept of 'Ba': Building a foundation for knowledge creation. California management Review, Vol. 40 No. 3, pp. 40-55.

Nonaka, I. and Takeuchi, K. (1995), The Knowledge Creating Company: How Japanese Companies Create the Dynamics of Innovation, Oxford University Press, Oxford.

McAdam and McCreedy, (1999), A critical review of Knowledge Management models. The Learning Organization, Vol. 6 No. 3, pp. 91 101.

Ott, S. (1989), The organizational culture perpective, Richard S. Irwin Inc.

Park, H., Ribiere, V. and Schulte, W.D. (2004), "Critical attributes of organisational culture that promote knowledge management technology implementation success" Journal of Knowledge Management, Vol. 8 No. 3, pp. 106-17.

Raub, S. and Von Wittich, D. (2004), "Implementing knowledge management: three strategies for effective CKOs", European Management Journal, 22 (6), 714-24.

Rhodes, J., Hung R., Lok, P., Lien, B.Y.H and Wu, C.M (2008), Factors influencing organizational knowledge transfer: implication for corporate performance, Journal of Knowledge Management, Vol. 12 No. 3, pp. 84-100.

Saito, A., Umemoto, K. and Ikeda, M. (2007), A strategy-based ontology of knowledge management technologies, Journal of Knowledge Management, Vol. 11 No. 1, pp. 97-114.

Schein, E.H. (1985), Organizational culture and leadership, San Francisco, CA: Jossey-Bass.

Soliman, F. and Spooner, K. (2000), "Strategies for implementing knowledge management: role of human resources management", Journal of Knowledge Management, Vol. 4 No. 4, pp. 337-45.

Stankosky and Baldanza (2001), A Systems Approach To Engineering A KM System. Unpublished manuscript.

Tiwana, A. (2002), The Knowledge Management Toolkit: Orchestrating IT, Strategy, And Knowledge Platforms. Prentice Hall, Upper Saddle River.

Wasko, M. \& Faraj, S. (2000), It is what one does: Why people participate and help others in electronic communities of practice. Journal of Strategic Information Systems, Vol. 9 No. 2-3), pp. 155-173.

Weeks, M. (2004), Knowledge management in the wild, Business Horizons, Vol. 47 No. 6, pp. 15-24.

Wiig, K. M. (1997), Knowledge Management: An Introduction and Perspective. The Journal of Knowledge Management, Vol. 1 No. 1, pp. 6-14. 